\title{
C. Cooperativismo no agronegócio: uma investigação sobre o alinhamento estratégico entre dirigentes e cooperados
}

Donizeti Leandro de Souza ${ }^{1}$

Lilian Ferrugini²

Agda Silva Prado 3

\section{Resumo}

Este estudo propõe diagnosticar os alinhamentos estratégicos e os conflitos de interesses entre os gestores e os cooperados de uma cooperativa agropecuária. Para tanto, foi realizada uma pesquisa qualitativa com 29 cooperados e 2 gestores de uma cooperativa agropecuária do Sul de Minas Gerais, caracterizando-se como um estudo de caso. Dentre os principais resultados, identificou-se que a cooperativa deve valorizar os aspectos que envolvem os conhecimentos do estatuto, as taxas administrativas perante os cooperados, e elaborar estratégias capazes de estimular a maior participação dos cooperados nas assembleias, para que a cooperativa fortaleça a abordagem comportamental focada na confiança, transparência e comprometimento, como uma perspectiva mais viável para a criação de vantagens competitivas para a cooperativa e cooperados. Em razão da representatividade que as cooperativas possuem no setor agropecuário, o estudo se mostra relevante pela necessidade das cooperativas de atentarem ao alinhamento estratégico com os interesses dos cooperados, de forma a buscar o bem comum entre seus cooperados e o consequente fortalecimento do agronegócio da região.

Palavras-chave: Cooperativismo. Agronegócio. Alinhamento Estratégico. Abordagem comportamental.

\section{Introdução}

A livre cooperação entre pessoas com interesses comuns esteve presente na vida humana desde a antiguidade. O espírito cooperativista sempre assumiu uma importante contribuição para a vida humana, no desenvolvimento pessoal, cultural e econômico de diversos povos. Na atual literatura sobre movimentos cooperativistas, percebe-se que as ações cooperativistas têm assumido duas abordagens conflitantes: de um lado a abordagem econômica, na qual os relacionamentos são baseados em interesses financeiros, gerados por meio de comportamentos oportunistas, fortes proteções formais e legais; do outro lado, tem-se a abordagem comportamental, focada no compromisso, coordenação, interdependência e confiança como importantes pilares para a sobrevivência do movimento cooperativista (LAGO; SILVA, 2012).

Nessa perspectiva, nota-se que a abordagem comportamental, focada em relações de confian-

\footnotetext{
1 Instituto Federal de Educação, Ciência e Tecnologia do Sul de Minas Gerais/Universidade Federal de Lavras, professor pesquisador. Três Corações, Minas Gerais, Brasil. donizeti.souza@ifsuldeminas.edu.br. (35) 3232-9494. Rua Cel. Edgar Cavalcanti de Albuquerque, 61, Chácara das Rosas, CEP 37.410-000.

2 Instituto Federal de Educação, Ciência e Tecnologia do Sul de Minas Gerais/Universidade Federal de Lavras, pesquisadora de doutorado. Lavras, Minas Gerais, Brasil. lilianufjf@yahoo.com.br. (035) 3829-1446. UFLA - Cx. P. 3037, Lavras, Minas Gerias, CEP 37.200-000.

3 Instituto Federal de Educação, Ciência e Tecnologia do Sul de Minas Gerais/Universidade Federal de Lavras, pesquisadora de mestrado. Lavras, Minas Gerais, Brasil. agdasprado@yahoo.com.br. (035) 3829-1446. UFLA - Cx. P. 3037, Lavras, Minas Gerias, CEP 37.200-000.
} 
ça e comprometimento, se apresenta como uma perspectiva viável a estudos de cooperação e criação de vantagens competitivas, pois aproximam as cooperativas dos modelos organizacionais substantivos, pela presença de preocupação com a condição humana, harmonizando a autonomia e os anseios individuais com os interesses coletivos (SERVA, 1993; BARNEY; HANSEN, 1994; JONES, 2004).

No entanto, para que uma organização cooperativista se mantenha no mercado e proporcione benefícios para seus cooperados, Zylbersztajn (2002) orienta que as definições estratégicas, capazes de aprimorar controles e tornar as cooperativas mais visíveis para o mercado, só terão efeitos positivos quando oriundos de estratégias que garantam a sobrevivência das cooperativas por meio de arranjos capazes de atuar nos diversos mercados, competindo com outros arranjos institucionais.

Machado Filho, Marino e Conejero (2004) sugerem que a implementação da análise estratégica, em organizações cooperativistas, é importante para a identificação de ameaças e oportunidades, o encaminhamento de soluções por meio de eventuais redirecionamentos estratégicos, redesenho de estruturas organizacionais e processos de tomada de decisões.

Nesse contexto, esse estudo propõe diagnosticar os alinhamentos estratégicos e os conflitos de interesses entre os gestores e os cooperados de uma cooperativa agropecuária de Minas Gerais, em que a agricultura se apresenta como principal atividade econômica local, e a cafeicultura, uma das principais atividades desenvolvidas pelos cooperados. Tal fato justifica a análise do ponto de vista da cooperação, para que a cooperativa se mantenha fortalecida e atinja o bem comum entre seus membros.

\section{Referencial teórico}

O termo "cooperativismo" deriva etimologicamente da palavra latina cooperari que, num sentido mais amplo, significa agir simultaneamente ou coletivamente com outros para um mesmo ideal, trazendo um senso de trabalho em comum para o sucesso de um mesmo propósito. A livre cooperação entre pessoas esteve presente na vida humana desde a antiguidade, sendo esse espírito cooperativista importante para a contribuição humana, no que tange ao desenvolvimento pessoal, cultural e econômico de diversos povos (OCEMG, 2010).

Entre as principais funções do cooperativismo, destacam-se o aspecto econômico, na geração de riquezas por meio de movimentos coletivos entre atores sociais, e o aspecto social, responsável por garantir o desenvolvimento e a sustentabilidade dos agentes envolvidos e da região onde eles estão inseridos (LAGO; SILVA, 2012).

A lei 5.764/71 define cooperativismo como sociedades de pessoas que, reciprocamente, se ajudam com bens ou serviços para o exercício de uma atividade econômica de proveito comum (BRASIL, 1971). Contudo, cooperar vai muito além do simples ato de organizar cooperativas. É, sobretudo, um modelo de gestão organizado por meio de valores mutualistas que se transformam num importante recurso capaz de superar dificuldades socioeconômicas, de forma que a união dos esforços pode fazer que as pessoas realizem ações e obtenham resultados dificilmente alcançáveis individualmente (SCOPINHO, 2007; SEBRAE, 2009; OCEMG, 2012).

Num comparativo com outros tipos de sociedades, Lomar (2007, p.53) afirma que "uma das características marcantes das cooperativas é ser ela uma sociedade de pessoas e não de capital". As sociedades cooperativas diferem dos demais modelos organizacionais existentes por apresentar vantagens quanto aos benefícios sociais e educativos oferecidos aos cooperados, pelo impacto social gerado na comunidade, pela diferenciação tributária e, principalmente, pela forma democrática de 
gestão com que as cooperativas são dirigidas e controladas pelos cooperados.

Cançado (2007) corrobora esses conceitos e acrescenta que, enquanto nas organizações comerciais o objetivo é o lucro e a gestão é definida por quem controla financeiramente a organização, nas cooperativas o objetivo básico consiste em prestar serviços aos cooperados, viabilizando e desenvolvendo a produção e o consumo, possibilitando que os cooperados se apropriem de seu trabalho sem a intermediação de terceiros. Da mesma maneira, sua gestão tende a ser diferenciada das sociedades mercantis, pois as cooperativas devem ser organizações democráticas, em que cada cooperado, independente do grau de investimento na organização, tem direito a um voto e tem voz ativa nas ações de gestão.

Por fim, segundo Gawlak e Ratzke (2010) e OCEMG (2012), o cooperativismo deve assumir sete princípios fundamentais como linhas orientadoras de valores e práticas, a saber: adesão voluntária e livre; gestão democrática pelos cooperados; participação econômica dos cooperados; autonomia e independência; educação, formação e informação; cooperação entre cooperativas e interesse pela comunidade.

\section{Abordagens cooperativistas}

$\mathrm{Na}$ atual literatura sobre movimentos cooperativistas, percebe-se que duas abordagens têm se destacado: a abordagem econômica, na qual os relacionamentos são baseados em interesses financeiros gerados por meio de comportamentos oportunistas, fortes proteções formais e legais; e a abordagem comportamental, focada no compromisso, coordenação, interdependência e confiança como importantes pilares para a sobrevivência de uma cooperativa (LAGO; SILVA, 2012).

Sob essas perspectivas, as formas de cooperação podem ser estudadas por meio das relações híbridas de interesses que combinam cooperação e competição em aspectos mutuamente opostos, explicados por três mecanismos fundamentais de relacionamento: (1) quando a cooperação desempenha um papel central; (2) quando a competição assume uma posição central e (3) quando a cooperação e a competição desempenham papéis iguais, refletindo a tensão entre a criação de valor pela cooperação e a apropriação de valor pela competição (LACOSTE, 2012).

Dessa dualidade de abordagens econômicas e comportamentais, uma das preocupações dos gestores tem sido encontrar formas para direcionar as ações estratégicas para um correto equilíbrio dos aspectos financeiros e sociais, administrando riscos, incertezas e ações oportunistas para tornar as ações cooperativistas mais eficientes. Desse desafio surge a necessidade de esforços organizacionais na identificação, persuasão e sinergia dos cooperados por meio de relações de confiança e governabilidade, em que as decisões de cooperação possam ser modeladas, evitando conflitos e facilitando a troca de recursos e a coordenação de esforços coletivos (NOHRIA; ECCLES, 1992; BORGATTI; FOSTER, 2003; CHAUVET et al., 2011).

Nohria e Eccles (1992), por meio de estudos sobre redes organizacionais, já destacavam a importância de esforços organizacionais na identificação, persuasão e sinergia de indivíduos em prol de esforços coletivos comuns. As relações existentes em um sistema social poderiam servir de trilha para um fluxo de informações capaz de produzir relações de confiança e governabilidade do sistema, sendo as decisões de cooperação entre as partes modeladas pela rede de relacionamento estabelecida.

Nessa perspectiva, nota-se que a abordagem comportamental, focada em relações de confian-

ça e comprometimento, se apresenta como uma perspectiva viável para estudos de cooperação como instrumento de vantagens competitivas, pois aproximam as cooperativas de modelos organizacionais 
substantivos, pela existência de uma nítida preocupação com a condição humana, conciliando a autonomia e os anseios individuais com os interesses coletivos (SERVA, 1993; BARNEY; HANSEN, 1994; JONES, 2004). Sob essa concepção, emerge uma gestão democrática de mecanismos informais por meio de trocas que apresentam múltiplas dimensões, assumindo grande relevância nas relações sociais e no próprio contexto em que as relações cooperativistas se constituem (VIZEU, 2009; OCEMG, 2012).

O cooperativismo assume um modelo de gestão no qual a sociedade se organiza pela ajuda mútua de seus membros para resolver problemas rotineiros, de forma que a união dos esforços em prol de um objetivo coletivo comum seja capaz de fazer que pessoas realizem ações e obtenham resultados dificilmente alcançáveis individualmente (SEBRAE, 2009; OCEMG, 2012).

De acordo com os dados da Organização das Cooperativas do Brasil (OCB, 2012), cada vez mais os brasileiros aderem ao cooperativismo. Somente no ano de 2011, aproximadamente 370 mil brasileiros tornaram-se cooperativistas, um aumento de $4 \%$ na comparação com 2011 , representando um total de 10,4 milhões de cidadãos associados até dezembro de 2012. A expectativa, até 2016, é chegar a 12 milhões de cooperativistas.

O modelo cooperativista de produção e prestação de serviços está presente em todos os setores da economia, em 13 ramos de atividades, e o ramo que possui maior participação de mercado é o agropecuário. Segundo o Instituto Brasileiro de Geografia e Estatística (IBGE), atualmente, 50\% de toda a produção agropecuária brasileira passa por 1.528 cooperativas ( $23 \%$ do total) em todo Brasil (OCB, 2012).

No setor agropecuário, alguns números demonstram a importância e a capacidade das cooperativas como instrumentos capazes de envolver e mobilizar pessoas/empresas em prol de atividades que podem prestar serviços diversos, além da comercialização de produtos. De acordo com o relatório anual da Organização das Cooperativas do Estado de Minas Gerais (OCEMG, 2012), ano base 2011, somente em Minas Gerais, as receitas advindas com cooperativas do setor agropecuário somaram em torno de R\$ 14 bilhões, representando 208 cooperativas e 160.393 (mil) cooperados, sendo 99.192 (mil) ativos e um total de 18.504 (mil) funcionários diretos das cooperativas. Tais dados demonstram a capacidade de geração de emprego e renda que as cooperativas agropecuárias proporcionam para o Estado.

Em decorrência da representatividade que as cooperativas possuem no setor agropecuário, torna-se necessária a busca pelo alinhamento estratégico entre os interesses das cooperativas com os interesses dos cooperados, de forma a fortalecer o agronegócio nas regiões em que estão inseridas. Para isso, Zylbersztajn (2002) orienta que as definições de estratégias capazes de aprimorar controles e tornar as cooperativas mais visíveis para o mercado só terá efeito positivo, no seu aprimoramento organizacional, quando oriundos de estratégias que garantam a sobrevivência das cooperativas, indicando serem arranjos factíveis capazes de atuar nos diversos mercados.

Para que isso ocorra, Machado Filho, Marino e Conejero (2004) sugerem que a implementação da análise estratégica em organizações cooperativistas torna-se fundamental para a identificação de ameaças e oportunidades, encaminhamento de soluções por meio de eventuais redirecionamentos estratégicos, redesenho de estruturas organizacionais e processos de tomada de decisões.

\section{Metodologia}

Como forma de analisar o alinhamento estratégico em organizações cooperativistas, foi realizado um estudo de caso em uma cooperativa agropecuária do Sul de Minas Gerais, com o propósito 
de diagnosticar os alinhamentos e os conflitos de interesses entre gestores e cooperados. Mais especificamente, buscaram-se identificar o perfil/interesses dos cooperados, as ações e interesses dos dirigentes e verificar a existência de alinhamentos estratégicos entre os interesses de cooperados e de dirigentes como fontes de valores coletivos e criação de vantagens competitivas.

O método de estudo de caso busca explorar situações da vida real, cujos limites não estão claramente definidos (GIL, 2002). Assim, a pesquisa se caracteriza como descritiva, por descrever as características de determinada população ou fenômeno. Caracteriza-se, também, como exploratória, por investigar novos construtos relacionados ao cooperativismo não identificados na literatura.

Quanto ao tipo de pesquisa, o estudo se caracteriza como qualitativo, realizado por meio de entrevistas semiestruturadas, por conveniência, junto a 29 (vinte e nove) cooperados (4,83\% dos cooperados ativos totais) e 2 (dois) gestores da cooperativa (departamento administrativo e departamento técnico), sendo utilizada a técnica de análise de conteúdo para organização dos resultados. 0 único critério empregado para a seleção dos cooperados foi que eles deveriam possuir a quota-parte no próprio nome, a fim de obter dados relevantes ao objeto de estudo.

\section{Resultados e discussão}

Analisando o perfil dos cooperados, os dados apontam que 75,9\% são casados, a maioria (37,9\%) está na faixa etária entre 46 a 55 anos e 58,6\% possuem o ensino fundamental incompleto. Sobre a atividade agrícola, a maioria dos cooperados (37,9\%) está envolvida no campo entre 31 e 40 anos, e a grande parte dos entrevistados (44,8\%) possuem propriedades entre 6 a 15 hectares. Para $96,6 \%$ dos cooperados, a atividade rural é a principal fonte de renda, em que o cultivo predominante é a cafeicultura (100\%) e a segunda atividade mais citada é a bovinocultura leiteira (31\%). 0 perfil diagnosticado corrobora com o perfil dos cooperados envolvidos no sistema agroindustrial caracterizado por Machado Filho, Marino e Conejero (2004), os quais afirmam que o sistema cooperativista agroindustrial distingue-se pela associação de um grupo (normalmente pequeno) de produtores, em geral com uma base cultural comum, voltados para algumas atividades agrícolas específicas, reunidas sob um arcabouço organizacional e institucional próprio.

Analisando a sua estrutura organizacional, os dados apontam que a cooperativa atua há 56 anos no mercado e seus departamentos estão estruturados da seguinte forma: o departamento operacional é subdivido em departamento comercial, responsável pela compra e venda de insumos; o departamento de café, que realiza armazenagem e comercialização aos cooperados; o departamento técnico, que realiza assistência técnica ao produtor e o departamento administrativo, responsável pelas funções financeiras e contábeis. Verifica-se, portanto, que existem estruturas especializadas de controle que facilitam a gestão da cooperativa, assim como afirmado por Zylbersztajn (2002).

A cooperativa possui 46 funcionários e 900 cooperados. Desse total, 600 são considerados como cooperados ativos. Os dados apontam uma efetividade relevante na capacidade operacional da cooperativa, pois, ao compararmos os dados apresentados pela OCEMG (2012), a média no Estado de Minas Gerais é de 5,36 cooperados ativos por funcionário, e, na cooperativa estudada, a média representa 13,04 cooperados ativos por funcionários, uma relação 243,34\% maior do que a média das cooperativas mineiras.

Para a cooperativa arcar com os custos operacionais e despesas efetuadas no armazém de café (movimentação, armazenagem e seguro), é cobrado um percentual sobre o valor da saca de café vendida, sendo esta taxa considerada pública. Outras taxas, consideradas não públicas, são embutidas 
nos preços dos insumos para custear a organização e a remuneração paga aos colaboradores. Assim, aspectos de transparência tornam-se importantes para a cooperativa se comunicar com o público interno, visto que essas taxas são importantes fontes de recursos. A abertura das informações pelas cooperativas pode permitir decisões de melhor qualidade pela gestão da organização, bem como do próprio cooperado a ela conectado (ZYLBERSZTAJN, 2002).

Em relação às dificuldades encontradas para promover o crescimento da cooperativa, destacam-se os de origem estruturais (infraestrutura e mão de obra), pois atualmente a estrutura existente não está sendo compatível com as necessidades da organização e por isso estão ocorrendo grandes investimentos neste aspecto. Os planos, propostas e estratégias consideradas pela cooperativa envolvem a construção de uma nova sede comercial mais ampla para ofertar linhas de produtos mais diversificados e uma nova estrutura para benefício do café. 0 interesse em alcançar esse objetivo está traçado por uma meta de no máximo três anos.

Para um melhor desempenho das vendas de insumos agrícolas aos cooperados, a cooperativa em pauta participa de uma central - ao todo são 20 cooperativas - responsável pelas compras que, em maior volume, conquista menores preços nas negociações e os repassa aos associados. Outra parceria é realizada com fornecedores para conquistar melhores condições e tecnologias mais avançadas, sem o que, na visão dos gestores, as negociações seriam inviabilizadas.

Outra parceria evidenciada se refere à comercialização do café dos cooperados. Tal parceria é feita por meio de um programa realizado por uma empresa de defensivos agrícolas que auxilia as propriedades cafeeiras a realizarem um melhor manejo da lavoura, incluindo rastreabilidade e responsabilidade ambiental. Com isso, os produtores envolvidos nesse programa estão conseguindo acessar o mercado externo. No momento, a cooperativa não se interessa por realizar exportações diretas de todo seu café comercializado em razão dos problemas estruturais, tais como infraestrutura e mão de obra qualificada, os quais devem ser prioritariamente resolvidos. Por fim, outro trabalho realizado pela cooperativa diz respeito ao apoio oferecido às associações rurais presentes no município, com uma agenda de participação igualitária para todas as associações, envolvendo trabalhos de dias de campo e reuniões entre os membros de cada associação.

Do ponto de vista dos gestores entrevistados, dentro de uma cooperativa deve prevalecer o benefício ao produtor, ou seja, ao cooperado. Quando as ações são demonstradas com transparência e seriedade, os gestores acreditam que a participação dos cooperados possa ser maior e mais efetiva. Nesse caso, percebe-se que a cooperativa busca se integralizar com os cooperados, a partir de atitudes proativas para manter a organização e fortalecer seus membros/cooperados.

\section{Análise do envolvimento dos cooperados com a cooperativa}

Analisando o envolvimento dos cooperados com a cooperativa, verifica-se que a maior proporção de cooperados está associada há um período que vai de 6 a 20 anos (55,2\% do total). Além disso, $82,8 \%$ afirmam não serem associados em outras cooperativas, fato positivo para a organização, pois demonstra a fidelidade da maioria de seus associados. Com isso, não se corre o risco de levar à perda de valor dos ativos investidos, o que dificultaria o planejamento de longo prazo e a estabilidade das relações entre as partes (ZYLBERSZTAJN, 2002).

A cooperativa promove anualmente uma assembleia geral ordinária, de acordo com seu estatuto, evento este que se constitui da deliberação dos seguintes assuntos: I - prestação de conta dos órgãos de administração, acompanhada do parecer do Conselho Fiscal, compreendendo o relatório 
de gestão; balanço e demonstrativo de sobras apuradas ou das perdas decorrentes da insuficiência das contribuições para cobertura das despesas da Sociedade. II - destinação das sobras apuradas ou rateio das perdas decorrentes da insuficiência das contribuições para cobertura das despesas da Sociedade, deduzindo-se, no primeiro caso, as parcelas para os fundos obrigatórios. III - eleição dos componentes do Conselho de Administração e do Conselho Fiscal, quando for o caso. IV - fixação do valor dos honorários, pró-labore ou verbas de representação para os membros do Conselho de Administração, bem como o da cédula de presença, para os membros do Conselho Fiscal, pelo comparecimento às respectivas reuniões. $\mathrm{V}$ - quaisquer assuntos de interesse social.

Com esses itens, percebe-se a importância da assembleia para a cooperativa, pois é nessa ocasião que várias decisões de ordem administrativa são tomadas, e delas norteará o funcionamento da cooperativa como um todo. De acordo com o presente estatuto, tais decisões devem ser tomadas pelos próprios cooperados presentes, discutindo em sociedade e votando os assuntos que nela forem tratados.

Mediante a importância desse evento, durante as entrevistas, procurou-se saber dos cooperados como eles consideram sua participação em assembleias organizadas pela cooperativa. Do total, apenas $17,2 \%$ afirmam participar dessas reuniões, grande parcela $(48,3 \%)$ afirma que raramente participa e 17,2\% afirmam nunca participar das assembleias. Verifica-se, assim, a baixa participação dos cooperados e a consequente perda do poder de decisão na instituição.

Sobre o conhecimento burocrático que envolve a cooperativa, apesar da disponibilidade do estatuto aos cooperados, 89,7\% declaram não conhecer tal documento, o que mostra um baixo interesse em conhecer os regimentos que norteiam a cooperativa, além dos direitos e dos deveres que possuem como cooperados.

Outro fato analisado é o desconhecimento sobre as taxas administrativas cobradas nos serviços de armazenamento, movimentação e seguro do café comercializado pela cooperativa. Dentre os pesquisados, 72,4 \% afirmam não conhecer tal taxa. Como relatado pela gerência, essa taxa é apresentada aos cooperados e considerada como pública. Verifica-se, então, que não há um entendimento entre os cooperados, como afirma a gerência, sendo necessário esclarecer melhor quais são as taxas e o motivo pelas quais elas são cobradas.

Quanto à porcentagem do total de café comercializado na cooperativa, verificou-se que, em média, $85 \%$ de todo café produzido pelos cooperados são comercializados pela cooperativa, e os demais $15 \%$ são vendidos por outros meios, como armazéns gerais ou corretores de café presentes no município. Apesar da baixa porcentagem, faz-se necessário verificar o motivo pelos quais os cooperados estão agindo dessa maneira, pois, caso 100\% do café produzido pelos cooperados fosse comercializado pela cooperativa, haveria mais recursos para a instituição, proporcionando, assim, maiores retornos aos próprios cooperados.

Quanto à percepção que os cooperados possuem da atuação da direção, verificou-se que a maioria considera "Bom" o trabalho dos dirigentes. Ao serem questionados sobre a quem se dirigem para apresentar novas ideias, críticas ou sugestões sobre a cooperativa, grande parte dos cooperados $(41,4 \%)$ remete à diretoria, 44,8\%, aos funcionários e 13,8\% não opinaram.

Pelos resultados obtidos, verifica-se que o trabalho dos dirigentes é bem avaliado, porém eles são menos procurados que os funcionários para críticas ou sugestões. Uma das causas pode ser justificada pela maior proximidade dos funcionários com os cooperados nas compras/vendas ou assistência técnica realizadas. Nesse caso, passa a ser de suma importância que os dirigentes busquem maiores informações com o corpo colaborativo da cooperativa, a fim de diagnosticar quais melhorias 
devem ser tomadas e os principais entraves percebidos pelos cooperados.

Por fim, verificando as expectativas, críticas ou sugestões dadas pelos cooperados em relação à cooperativa, dos 29 entrevistados, nenhum cooperado expôs alguma crítica e apenas 1 (um) sugeriu que houvesse maior número de pessoas para atender no departamento de vendas de café. Ressalta-se, ainda, que $37 \%$ possuem expectativas de melhoras com a construção da sede nova e $20 \%$ esperam que a cooperativa trabalhe dentro de uma perspectiva de melhoria contínua.

Mediante os dados apresentados, é possível traçar uma síntese do comparativo entre os pontos positivos e negativos identificados na pesquisa.

Quadro 1: Pontos positivos e negativos de alinhamentos estratégicos

\begin{tabular}{|c|c|c|c|c|}
\hline & Cooperativa & Cooperado & Cooperativa & Cooperado \\
\hline Tempo de atuação & $\begin{array}{l}\text { Cooperativa há } 56 \\
\text { anos no mercado }\end{array}$ & $\begin{array}{l}\text { Cooperados envolvidos } \\
\text { há um longo tempo na } \\
\text { atividade rural }\end{array}$ & + & + \\
\hline Planos futuros & $\begin{array}{l}\text { Estratégias voltadas } \\
\text { para a construção da } \\
\text { nova sede }\end{array}$ & $\begin{array}{l}\text { Expectativa de melhoras } \\
\text { com construção da nova } \\
\text { sede }\end{array}$ & + & + \\
\hline Estatuto & $\begin{array}{l}\text { A cooperativa torna } \\
\text { público seu estatuto }\end{array}$ & $\begin{array}{l}\text { A maioria dos cooperados } \\
\text { afirma não conhecer o } \\
\text { estatuto }\end{array}$ & + & - \\
\hline $\begin{array}{l}\text { Participação em } \\
\text { assembleias }\end{array}$ & $\begin{array}{c}\text { Busca integralizar os } \\
\text { cooperados }\end{array}$ & $\begin{array}{c}\text { Baixa participação dos } \\
\text { cooperados em assembleias }\end{array}$ & + & - \\
\hline Taxas administrativas & $\begin{array}{c}\text { Reconhece que não } \\
\text { torna públicas as taxas } \\
\text { de comercialização }\end{array}$ & $\begin{array}{l}\text { Desconhecimento pela } \\
\text { maioria sobre as taxas } \\
\text { administrativas cobradas }\end{array}$ & - & - \\
\hline Comercialização & $\begin{array}{l}\text { Desenvolve parcerias } \\
\text { para preços mais } \\
\text { competitivos }\end{array}$ & $\begin{array}{c}\text { Alta frequência de } \\
\text { negociações realizadas }\end{array}$ & + & + \\
\hline Interação da diretoria & $\begin{array}{l}\text { Alta interação com } \\
\text { as associaç̃̃es rurais } \\
\text { e boa avaliação dos } \\
\text { cooperados }\end{array}$ & $\begin{array}{l}\text { Baixa comunicação dos } \\
\text { cooperados com a diretoria }\end{array}$ & + & - \\
\hline
\end{tabular}

Fonte: Dados da pesquisa

Verifica-se, por esses dados, a necessidade de a cooperativa valorizar os aspectos que envolvem os conhecimentos do estatuto e das taxas administrativas, assim como elaborar estratégias para uma maior participação dos cooperados nas assembleias, de forma que a cooperativa esteja alinhada com os interesses dos cooperados. Ademais, faz-se necessária uma aproximação maior da diretoria com os cooperados para que os alinhamentos estratégicos estejam de comum acordo entre ambas as partes.

\section{Conclusões}

Para que uma organização cooperativista se mantenha no mercado e alcance benefícios, é necessário que a coletividade se sobreponha à individualidade, contribuindo positivamente para relações comportamentais de confiança, compromisso e idealismo entre cooperativas e cooperados. Assim, conclui-se que a cooperativa pesquisada é uma instituição de grande importância para os produtores rurais do município, pois mostra capacidade de viabilizar a comercialização de café de seus cooperados. Entretanto, nota-se que alguns pontos devem ser melhorados pela instituição, a fim de incentivar os cooperados a se engajarem mais nas ações da cooperativa. 
Entre as ações estratégicas a serem melhoradas, destacam-se o incentivo ao conhecimento do estatuto da organização, a participação nas assembleias e a transparência nas taxas administrativas. Esses são considerados elementos essenciais para o fortalecimento da abordagem comportamental focada na confiança, transparência e comprometimento, como uma perspectiva mais viável para a criação de vantagens competitivas para a cooperativa e cooperados (BARNEY; HANSEN, 1994; JONES, 2004; LAGO; SILVA, 2012; OCEMG, 2012).

Por fim, deve-se destacar que a pesquisa apresenta algumas limitações ao abordar um único caso e uma quantidade limitada de cooperados pesquisados. Contudo, demonstra potencialidade para a realização de novos estudos, a fim de diagnosticar o conceito que cada cooperado possui sobre o significado de uma instituição cooperativista. Esse conhecimento propiciará que todos reconheçam o real papel de uma cooperativa, o que acabará por fortalecer o grupo. Ademais, o estudo é útil ao explorar fatores que contribuem para um alinhamento estratégico capaz de fortalecer os movimentos cooperativistas por meio de interesses comuns.

\title{
Cooperativeness in Agribusiness: An investigation into the strategic alignment between managers and cooperative members
}

\begin{abstract}
This study proposes diagnosing strategic alignments and interest conflicts between managers and cooperators of an agricultural cooperative in Minas Gerais state. We carried out a qualitative research with 29 cooperatives and 2 managers of an agricultural cooperative in Minas Gerais, as a case study. Among the main results, we found out that the cooperative should value those aspects that involve knowledge of the statute, administrative charges towards the cooperative and elaborate strategies to encourage the participation of cooperative members meetings to strengthen cooperative behavioral approach focused on trust, transparency and commitment as a perspective to create competitive advantages for cooperatives and cooperative. Because the representation those cooperatives have in agricultural area, the study was relevant to show the needs of cooperatives to increase the strategic alignment with members interests, in order to seek the common goods of its members and the consequent strengthening of agribusiness in the region.
\end{abstract}

Keywords: Cooperativeness. Agribusiness. Strategic alignment. Behaviorist approach.

\section{Referências}

BARNEY, J. B.; HANSEN, M. H. Trustworthiness as a source of competitive advantage. Strategic Management Journal, Sussex, v.15, p.175-190, 1994.

BORGATTI, S. P.; FOSTER, P. The network paradigm in organizational research: a review and typology. Journal of Management. n.29, v.6, p. 991-1013, 2003.

BRASIL. Lei 5.764 de 16 de Dezembro de 1971. Define a Política Nacional de Cooperativismo, institui o regime jurídico das sociedades cooperativas, e dá outras providências. Diário Oficial da União, Brasília, 17 dez. 1971.

CANÇADO, A. C. Autogestão em Cooperativas populares: Os desafios da prática. Salvador: IES, 2007. 
CHAUVET, V.; CHOLLET, B.; SODA, G.; HUAULT, I. The contribution of network research to managerial culture and practice. European Management Journal. v.29, p.321-334, 2011.

GAWLAK, A.; RATZKE, F. A. Cooperativismo: primeiras lições. 4.ed. Brasília: Sescoop, 2010.

GIL, A. C. Como elaborar projetos de pesquisa. 4.ed. São Paulo: Atlas. 2002.

JONES, E. C. Wealth-Based Trust and the Development of Collective Action. World Development v.32, n.4, p. 691-711, 2004.

LACOSTE, S. "Vertical coopetition": the key account perspective. Industrial Marketing Management, v.41, p.649-658, 2012.

LAGO, A.; SILVA, T. N. Condicionantes do desenvolvimento de relacionamentos intercooperativos no cooperativismo agropecuário. Organizações Rurais \& Agroindustriais, Lavras, v.14, n.2, p. 2012 226, 2012.

LOMAR, M. C. P. O Cooperativismo e a economia solidária: Discutindo o marco legal. In: A gestão da autogestão na economia solidária: contribuições iniciais. Organização Incubadora Tecnológica de Cooperativas Populares da Universidade de São Paulo; Núcleo de Gestão da ITCP-USP [et al.]. Porto Alegre: Calábria; São Paulo: ITCP-USP, 2007.

MACHADO FILHO, C. A. P.; MARINO, M. K.; CONEJERO, M. A. Gestão estratégica em cooperativas agroindustriais. Caderno de Pesquisas em Administração, São Paulo, v.11, n.2, p.61-69, 2004.

NHORIA, N.; ECCLES, R. G. Is a network perspective a useful way of studyng organizations? In: NHORIA, N.; ECCLES, R, G. Networks and organizations: structure, form and actions. Boston: Harvard business School press, 1992.

OCB - Organização das Cooperativas Brasileiras. Relatório OCB 2012 - Cooperativas constroem um mundo melhor. Disponível em: <http://www.brasilcooperativo.coop.br/ downloads/Gecom/relatorio_ocb_2012.pdf > . Acesso em 30 de Agosto de 2013.

OCEMG - Organização das Cooperativas do Estado de Minas Gerais. Livro comemorativo 40 anos OCEMG. Sistema OCEMG/SESCOOP-MG, Belo Horizonte, 2010.

OCEMG - Informações Econômicas e Sociais do cooperativismo mineiro. Sistema OCEMG/SESCOOP-MG. Belo Horizonte: Bigráfica. 2012.

SCOPINHO, R. A. Sobre Cooperação e Cooperativas em assentamentos rurais. Rev. Psicologia \& Sociedade, São Carlos, n.19, Edição especial 1, p.84-94, 2007.

SEBRAE - Serviço Brasileiro de Apoio às Micro e Pequenas Empresas. Cooperativa de crédito. Série empreendimentos coletivos, Brasília: Editora SEBRAE, 2009.

SERVA, M. O fenômeno das organizações substantivas. Revista de Administração de Empresas, v.33, n.2, p.36-43, 1993.

VIZEU, F. Contribuições da sociologia da dádiva aos estudos sobre organizações substantivas. O\&S, v.16, n.50, p.409-427, 2009. 
ZYLBERSZTAJN, D. Quatro estratégias fundamentais para cooperativas agrícolas. In: BRAGA, M. J.; REIS, B. S. (Orgs.). Agronegócio cooperativo: reestruturação e estratégias. Viçosa: UFV, 2002.

\section{Histórico editorial}

Submetido em: 27/05/2014

Aceito em: 30/10/2014 